\title{
Use of Flow-Diverting Devices in Fusiform Vertebrobasilar Giant Aneurysms: A Report on Periprocedural Course and Long-Term Follow-Up
}

L. Ertl, M. Holtmannspötter, M. Patzig, H. Brückmann, and G. Fesl

\begin{abstract}
BACKGROUND AND PURPOSE: Fusiform vertebrobasilar giant aneurysms are a rare ( $<1 \%$ of all intracranial aneurysms) but challenging aneurysm subtype. Little data are available on the natural history of this aneurysm subtype and the impact of the use of flow-diverting stents on the long-term clinical and imaging follow-up. In this article, we present our experience with the treatment of fusiform vertebrobasilar giant aneurysms by flow diverting stents. We aim to stimulate a discussion of the best management paradigm for this challenging aneurysm subtype.
\end{abstract}

MATERIALS AND METHODS: We retrospectively identified 6 patients with fusiform vertebrobasilar giant aneurysms who had been treated with flow-diverting stents between October 2009 and March 2012 in our center. The available data were re-evaluated. The modified Rankin Scale score was assessed before intervention, during the stay in hospital, and at discharge.

RESULTS: Six patients were identified (all male; age range, 49-71 years; median age, 60 years). Handling of material was successful in all cases. No primary periprocedural complications occurred. The mean follow-up was 13 months (15 days to 29 months). During follow-up, 3 of 6 patients had recurrent cerebral infarctions, but no patient experienced SAH. Two patients presented with acute thrombotic stent occlusion. The modified Rankin Scale score was not higher than 3 in any of the cases before intervention, whereas the best mRS score at the last follow-up was 5. Four of 6 patients died during follow-up.

CONCLUSIONS: Endovascular treatment of fusiform vertebrobasilar giant aneurysms with flow-diverting devices is feasible from a technical point of view; however, changes in hemodynamics with secondary thrombosis are not predictable. We currently do not intend to treat fusiform vertebrobasilar giant aneurysms with flow-diverting devices until we have further understanding of the pathophysiology, natural history, and hemodynamic effects of flow diversion.

ABBREVIATIONS: $A$ SA = acetylsalicylic acid; FVBGA = fusiform vertebrobasilar giant aneurysm

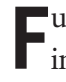
usiform vertebrobasilar giant aneurysms (FVBGAs) are a rare but important and challenging aneurysm subtype. The incidence of FVBGAs is estimated to be only $<1 \%$ of all intracranial aneurysms. ${ }^{1-12}$ Little is known about the natural history of FVBGAs, but the data available indicate poor outcome and continuous progression of aneurysm size and related symptoms (brain stem com-

\footnotetext{
Received August 29, 2013; accepted after revision November 4.

From the Department of Neuroradiology (L.E., M.P., H.B., G.F.), Institute of Clinical Radiology, Grosshadern Campus, University of Munich, Munich, Germany; and Center for Diagnostic Radiology (M.H.), Department of Neuroradiology, Rigshospitalet, University of Copenhagen, Copenhagen, Denmark.

Paper previously presented in part at: 47th Annual Meeting of the German Society of Neuroradiology, October 11-13, 2012; Cologne, Germany.

Please address correspondence to Lorenz Ertl, MD, Department of Neuroradiology, University of Munich, Grosshadern Campus, Marchioninistr 15, D-81377 Munich, Germany; e-mail: lorenz.ertl@med.uni-muenchen.de

http://dx.doi.org/10.3174/ajnr.A3859
}

pression, brain stem ischemia, subarachnoid hemorrhage in particular). ${ }^{13,14}$

The treatment of FVBGAs presents enormous challenges. Complex treatment objectives include prevention of hemorrhage, control of thromboembolic complications, and relief of mass effect. ${ }^{15}$ Anatomic predispositions limit therapeutic options to an endovascular approach with preservation of the parent artery and perforators. ${ }^{15}$ Flow-diverting stents, a new option in endovascular therapy specifically designed for endovascular reconstruction of circumscript segments of the main brain-supplying arteries, seem to be a therapeutic option. However little is known about the potential limitations and threats in the application of these devices in the vertebrobasilar arterial system. ${ }^{16-18}$

It is, thus, extremely difficult to decide whether to treat FVBGAs with flow-diverting devices. In this article, we present our experience with the treatment of FVBGAs by flow-diverting stents and the long-term clinical and imaging follow-up. We aim to 
Table 1: Treatment \& primary periprocedural complications

\begin{tabular}{llccc} 
No. & Material & $\begin{array}{c}\text { Several } \\
\text { Sessions }\end{array}$ & $\begin{array}{c}\text { Additional } \\
\text { Coiling }\end{array}$ & $\begin{array}{c}\text { Primary } \\
\text { Periprocedural } \\
\text { Complications }\end{array}$ \\
\hline 1 & $6 \times$ Pipeline & No & No & No \\
2 & $2 \times$ Silk, $3 \times$ LEO & No & No & No \\
3 & $2 \times$ Silk, $7 \times$ LEO + & Yes & No & No \\
4 & $2 \times$ Silk, $3 \times$ LEO & No & Yes & No \\
5 & $4 \times$ Silk, $4 \times$ LEO + & Yes & Yes & No \\
6 & $3 \times$ Silk & No & No & $0 / 6$ \\
Ratio & & $2 / 6$ & $2 / 6$ & \\
\hline
\end{tabular}

geons, neuroradiologists, vascular surgeons, neurologists, and radiotherapists.

An interdisciplinary decision in favor of an endovascular approach led to an honest, transparent, and open-outcome discussion with the patient and family, in which the current state of information was clearly presented. The discussion included the probably poor natural history of the disease and any complications associated with all meth- stimulate a discussion of the best management paradigm for this challenging aneurysm subtype.

\section{MATERIALS AND METHODS \\ Patient Selection}

We retrospectively reviewed the endovascular data base at the University of Munich Hospital, Großhadern Campus, and identified 6 patients with FVBGAs who had been treated between October 2009 and March 2012 with either Pipeline Embolization Devices (ev3, Irvine, California) or Silk flow-diverting stents (Balt Extrusion, Montmorency, France) (Table 1).

\section{Data Collection and Interpretation}

The available data, consisting of imaging and patient reports, were re-evaluated by 3 experienced neuroradiologists. Patient reports were reviewed to assess the preinterventional modified Rankin Scale scores ${ }^{19,20}$ and the clinical course, including symptoms before intervention, during the hospital stay, and at discharge. Additionally, patients or relatives were interviewed in our outpatient clinic or contacted by telephone to determine clinical symptoms during follow-up, current modified Rankin Scale scores and/or cause of death.

Follow-up imaging reviewed consisted of digital subtraction angiography and MR imaging examinations performed on a 3T scanner (Signa HDxt; GE Healthcare, Milwaukee, Wisconsin), including gradient-echo, diffusion-weighted imaging, T2WI and T1WI (with or without gadolinium), T2-weighted fluid-attenuated inversion recovery, and MR vascular imaging (3D time-offlight angiography and contrast-enhanced MR angiography). All images were re-evaluated with special regard to aneurysm size and location, intraluminal thrombus formation, stent patency, territorial ischemia, and/or intracranial hemorrhage.

Primary periprocedural complications were defined as any technical problems in the delivery of the device or as any clinical deterioration observed within the first 24 hours after the procedure. Due to the retrospective study design, institutional review board approval was not obtained.

\section{Indications and Decision-Making Process}

In all cases, the indication for an interventional approach was the result of an individual patient-based and interdisciplinary decision-making process. Endovascular therapy by flow diversion was considered in patients with acute or chronically deteriorating brain stem symptoms due to FVBGAs in combination with a high psychological strain on the patient. These patients were presented for discussion at a weekly case conference attended by neurosur- ods of treatment. All patients were made aware that the use of flow-diverting stents in this aneurysm subtype was not a firmly accepted therapeutic paradigm but an individualized investigational therapeutic approach. During the observation period, all patients were put on acetylsalicylic acid (ASA), $100 \mathrm{mg} /$ day. All patients received the best medical treatment to control other cardiovascular risk factors (hypertension and hypercholesterolemia in particular).

\section{Periprocedural Management}

All procedures were performed with the patient under intubation anesthesia conditions. Activated clotting time was continuously measured and elevated on a level of $>200$ seconds by heparin during the entire procedure. Adjunctive coiling to assist thrombosis of the aneurysm was performed when appropriate during the intervention. After the procedure, all patients were kept under surveillance, including continuous blood pressure monitoring, for at least 24 hours in a neurosurgical or neurologic intensive care unit.

All patients underwent a standardized closely monitored antiplatelet medication regimen. Tirofiban (Aggrastat) was intravenously administered with a loading dose of $0.4 \mu \mathrm{g} / \mathrm{kg} / \mathrm{min}$ for 30 minutes followed by a maintenance dose with a continuous perfusion rate of $0.1 \mu \mathrm{g} / \mathrm{kg} / \mathrm{min}$. At 12:00 AM on the first postinterventional day, 300-mg clopidogrel and 100-mg ASA were given orally, whereas 4 hours later (04:00 AM), tirofiban infusion was stopped. Therapeutic responses to tirofiban, clopidogrel, and ASA were monitored by Multiplate (Roche Diagnostics International, Rotkreuz, Switzerland) testing performed 15 minutes after the beginning of the tirofiban infusion, at the end of the intervention, and at 10:00 AM on first postinterventional day. During follow-up, a combination of clopidogrel, $75 \mathrm{mg} /$ day, and ASA, $100 \mathrm{mg} /$ day, was given for a minimum of 6 months followed by a life-long therapy with ASA, $100 \mathrm{mg} /$ day (Table 2).

\section{Study Devices}

Flow-diverting devices consist of a flexible, microcatheter-delivered, self-expanding, endovascular "stentlike" construct intended to create a laminar flow pattern in the parent artery and secondary thrombosis within the aneurysm, while keeping open the arterial perforators. ${ }^{21}$ Patients in this case series were treated with either Pipeline or Silk devices, the latter partially in a "telescoping technique," 22 combining LEO (Balt Extrusion) and Silk stents (Table 1).

AJNR Am J Neuroradiol 35:1346-52 Jul 2014 www.ajnr.org 
Table 2: Antiplatelet regimen timeline

\begin{tabular}{|c|c|c|c|c|c|c|}
\hline \multirow{2}{*}{$\begin{array}{l}\text { Observation } \\
\text { Period }\end{array}$} & \multicolumn{2}{|c|}{ Intervention } & \multicolumn{3}{|c|}{ Day 1 after intervention } & \multirow[b]{2}{*}{ Follow-Up Period } \\
\hline & Delivery of the First Stent & During Intervention & $12: 00$ АМ & 4:00 AM & 10:00 АM & \\
\hline \multirow[t]{3}{*}{ ASA 100 mg/day } & Tirofiban (Aggrastat) i.v., & Multiplate test & Clopidogrel 300 mg p.o. & $\begin{array}{l}\text { Tirofiban (Aggrastat) i.v., } \\
\text { stopped }\end{array}$ & Multiplate test & $\begin{array}{l}\text { 1) First } 6 \text { months clopidogrel } \\
75 \mathrm{mg} / \text { day and ASA } 100 \\
\mathrm{mg} / \text { day }\end{array}$ \\
\hline & $\begin{array}{l}\text { 1) loading dose, } 0.4 \\
\mu \mathrm{g} / \mathrm{kg} / \mathrm{min}(30 \mathrm{~min})\end{array}$ & 1) 15 min after tirofiban start, & ASA 100 mg p.o. & & $\begin{array}{l}\text { ASA response? } \\
\quad \text { clopidogrel response? }\end{array}$ & $\begin{array}{l}\text { 2) lifelong therapy } \\
\text { ASA } 100 \mathrm{mg} / \text { day }\end{array}$ \\
\hline & $\begin{array}{l}\text { 2) maintenance dose, } \\
0.1 \mu \mathrm{g} / \mathrm{kg} / \mathrm{min}\end{array}$ & $\begin{array}{l}\text { 2) end of the intervention, } \\
\text { tirofiban response? }\end{array}$ & & & & \\
\hline
\end{tabular}

Note:-p.o. indicates by mouth; i.v., intravenous.

Table 3: Clinical characteristics of the patients

\begin{tabular}{|c|c|c|c|}
\hline No. & Sex & Age (yr) & Symptoms Leading to Intervention \\
\hline 1 & M & 64 & Left-sided hemiplegia and facial nerve paresis, line-of-sight nystagmus to the left, dysarthria, dysphagia \\
\hline 2 & M & 71 & Diplopia, insecure gait, progressive aneurysm size, fear of death \\
\hline 3 & M & 65 & $\begin{array}{l}\text { Progressive right-sided hemiparesis, increasingly insecure gait with recurrent falls, clumsiness, and } \\
\text { sensory deficits in the right upper extremity }\end{array}$ \\
\hline 4 & M & 58 & $\begin{array}{l}\text { Recurrent episodes of dizziness, headache, tinnitus, sensory deficits in right arm and limb and acute } \\
\text { prepontine SAH }\end{array}$ \\
\hline 5 & M & 54 & Persistent central oculomotor disorder, progressive dysarthria, and latent monoparesis of the right limb \\
\hline 6 & M & 49 & $\begin{array}{l}\text { Diplopia due to abducens nerve paresis, dysphagia, hypesthesia of left face and hand, dysarthria, } \\
\text { instable gait }\end{array}$ \\
\hline Mean age (range) & & $60(49-71)$ & \\
\hline
\end{tabular}

Table 4: Anatomical and clinical findings during observation period

\begin{tabular}{|c|c|c|c|c|c|}
\hline No. & \multicolumn{2}{|c|}{ Aneurysm Location and Size $(\mathrm{cm})$} & \multirow{2}{*}{$\begin{array}{c}\text { Time between } \\
\text { Initial Diagnosis and } \\
\text { Procedure (mo) }\end{array}$} & \multirow{2}{*}{$\begin{array}{c}\text { Territorial Infarct } \\
\text { Prior to Procedure }\end{array}$} & \multirow{2}{*}{$\begin{array}{c}\begin{array}{c}\text { SAH Prior } \\
\text { to Procedure }\end{array} \\
\text { No }\end{array}$} \\
\hline 1 & BA/V4 & 2.2 & & & \\
\hline 2 & $\mathrm{BA}$ & 2.8 & 48 & No & No \\
\hline 3 & $\mathrm{BA} / \mathrm{V} 4$ & 2.0 & 13 & Yes, pericallosal & No \\
\hline 4 & BA/V4 & 1.3 & 4 & No & Yes \\
\hline 5 & $\mathrm{BA}$ & 3.0 & 29 & Yes, brain stem & No \\
\hline 6 & $\mathrm{BA} / \mathrm{V} 4$ & 2.1 & 3 & Yes, brain stem & No \\
\hline Mean (range, ratio) & & $2.23(1.3-3)$ & $17.5(3-48)$ & $4 / 6$ & $1 / 6$ \\
\hline
\end{tabular}

Note:-BA indicates basilar artery.

\section{RESULTS}

\section{Patient Collective}

Six patients were identified. They were all male. Age at the time of the decision to intervene ranged from 49 to 71 years (median, 60 years). Patients presented with a heterogeneous set of symptoms, mostly consistent with progressive brain stem dysfunction and compatible with the specific anatomic shape, size, and position of the underlying aneurysm in all cases (Table 3 ). In 4 patients (patients $1,3,5$, and 6), there was evidence of territorial infarction in preinterventional MR imaging. With the exception of patient 3, in whom the infarct was located in the vascular territory of the left posterior pericallosal artery ( $>10$ years ago), all infarcts were either in a brain stem or pontomedullary location (Table 3 ).

Only 1 patient (patient 4) had a FVBGA-induced acute subarachnoid hemorrhage during the observation period. Most interesting, the patient presented with a Glasgow Coma Scale score of 14 , when referred to our emergency department. In this case, the presence of an SAH was the determining factor in the decision to intervene (Tables 3 and 4 ). The wide range of observation periods (mean, 17.5 months; range, 3-48 months) was the result of the individualized decision-making process, mainly driven by individual clinical deterioration and changes in aneurysm shape and size (Table 4). All aneurysms were located in the basilar artery, 4 extending into the V4 segment of the left vertebral artery (patients 1, 3, 4, and 6). The maximum aneurysm diameter was $2.23 \mathrm{~cm}$ on average, ranging from 1.3 to $3.0 \mathrm{~cm}$ (Table 4 ).

\section{Intervention and Primary Periprocedural Complications}

The material and periprocedural course are summarized in Table 3. Four patients (patients 2, 3, 4, and 5) were treated with a combination of Silk and LEO or LEO+ stents in a "telescoping technique" to provide a scaffold of support. Patient 1 was treated with a series of overlapping Pipeline Embolization Devices, and patient 6 was treated solely with Silk stents (Table 1). In 2 patients (patients 4 and 5), the V4 segment of the right vertebral artery was occluded directly at the anatomic intersection to the basilar artery by coiling due to its contribution to the aneurysm supply. In 2 cases (patients 3 and 5), the procedure was split into 3 sessions on consecutive days to achieve optimum results of the flow-diversion effect (Table 1). The detachment of the stents and handling of material were successful in all cases. No primary periprocedural complications, according to our definition, were observed within the first 24 hours after the intervention (Table 1). No nonresponders on tirofiban, ASA, or clopidogrel were detected in Multiplate testing.

\section{Secondary Complications and Follow-Up}

Secondary complications and follow-up are summarized in Tables 5 and 6. Three of 6 patients (patients 3, 4, and 5) had recurrent cerebral infarctions in anatomic locations shown in Table 5. No patient experienced SAH during follow-up (Table 4). In all except 1 patient (patient 6), thrombotic occlusion of the aneurysm outside the stent was continuously progressive but incomplete during follow-up (Table 5). 
Table 5: Secondary complications during follow-up

\begin{tabular}{|c|c|c|c|c|}
\hline No. & Territorial Ischemia during FU & $\begin{array}{l}\text { SAH during } \\
\text { FU }\end{array}$ & $\begin{array}{l}\text { Complete Aneurysmal } \\
\text { Thrombotic Occlusion }\end{array}$ & Stent Occlusion during FU \\
\hline 1 & No & No & No & No \\
\hline 2 & No & No & No & No \\
\hline 3 & Yes, brain stem & No & No & $\begin{array}{l}\text { Stent occlusion (day 9) } \rightarrow \\
\quad \text { successful recanalization }\end{array}$ \\
\hline 4 & Yes, brain stem/cerebellum, thalamus/pontomedullary & No & No & $\begin{array}{l}\text { Stent occlusion (day } 32 \text { ) } \rightarrow \\
\quad \text { successful recanalization }\end{array}$ \\
\hline 5 & Yes, brain stem/cerebellum & No & No & No \\
\hline 6 & No & No & Yes & No \\
\hline Ratio & $3 / 6$ & $0 / 6$ & $1 / 6$ & $2 / 6$ \\
\hline
\end{tabular}

Note:-FU indicates follow-up.

Table 6: Follow-up and clinical outcome

\begin{tabular}{lcccl}
\hline No. & Duration Follow-Up & $\begin{array}{c}\text { mRS Prior to } \\
\text { Procedure }\end{array}$ & $\begin{array}{c}\text { mRS Last } \\
\text { Follow-Up }\end{array}$ & \multicolumn{1}{c}{ Cause of Death } \\
\hline 1 & $17 \mathrm{mo}$ & 3 & 6 & $\begin{array}{c}\text { Brain stem compression (due to secondary pneumonia) } \\
\text { Cardiac } \\
\text { Locked-in syndrome, dismissal of therapy at the request } \\
\text { of the patient and relatives }\end{array}$ \\
3 & $5 \mathrm{mo}$ & 3 & 6 & \\
4 & 12 days & 2 & 6 & Brain stem compression \\
5 & $17 \mathrm{mo}$ & 1 & 5 & - \\
6 & $29 \mathrm{mo}$ & 3 & 5 & \\
Mean (range) & $9 \mathrm{mo}$ & 3 & 6 & \\
\hline
\end{tabular}

Note:-mRS indicates modified Rankin Scale score.

Stents remained patent in most cases; however, 2 patients (patients 3 and 4) presented with acute thrombotic stent occlusion on days 9 and 32, respectively. Immediate interventional recanalization procedures were performed successfully; however, residual neurologic deficits were persistent in both cases (Table 5). In particular, growing thrombus formation led to an in-stent thrombosis $(\sim 80 \%)$ at the upper part of the stent construct of patient 3 . Neither local thrombolysis with 20-mg rtPA nor direct aspiration maneuvers showed significant effects. Partial recanalization of the stent construct could finally be achieved by using a $6 \times 3 \mathrm{~cm}$ Solitaire stent-retriever system (Covidien, Irvine, California). However, the final result showed an entry/re-entry flow pattern, which bypassed persistent in-stent stenosis via the nonthrombosed superior aneurysm part. Patient 4 presented with thrombotic occlusion of the proximal stent construct ranging from the V4 segment of the left vertebral artery into the middle basilar artery. Local thrombolysis with a total of 25-mg rtPA for $30 \mathrm{~min}$ utes and a singular aspiration maneuver resulted in complete recanalization of the stent and all arteries.

Follow-up was 13 months on average, ranging from 15 days to 29 months (Table 6). The mRS score was not higher than 3 in any of the cases before intervention, whereas the best mRS score at the last follow-up was 5 . As indicated in Table 6, four patients died during follow-up. In 2 cases, the clinical course and MR imaging indicated progressive brain stem compression leading to neurologic deficits. Related secondary pneumonia was the cause of death in patient 1 . Patient 2 died during the follow-up period due to a malignant cardiac arrhythmia and myocardial failure. Patient 3 had an extremely poor course with recurrent ischemia and thrombotic stent occlusion on day 9 after primary intervention. Despite a successful recanalization procedure, bilateral pontomedullary infarcts remained, leading clinically to a locked-insyndrome. The patient died on day 15 after the primary procedure (Tables 5 and 6).

\section{DISCUSSION}

FVBGAs still represent a worst case scenario for both patient and physician. Data available on the natural history of this disease suggest a progressive and fatal clinical course. The mortality rate is $23 \%-35 \%$ during 5 years. ${ }^{14,23,24}$ Death is mainly caused by cerebral infarction and brain stem compression, with spontaneous ruptures and consecutive subarachnoid hemorrhage occurring rather infrequently $(0.9 \%-2.3 \%$ a year $) .{ }^{14,24,25}$ The recent literature mentioned above represents the best available evidence to underpin therapeutic decisions. Mainly due to the rare occurrence of this type of fusiform aneurysm disease, the literature only consists of case series. Despite their important impact on clinical decision-making, the evidence level of these publications is thus limited.

The specific anatomic feature of the basilar artery with its multisegmental supply of the brain stem by numerous perforating branches rules out a vessel-occluding therapeutic approach. Previous treatment effort, surgical or endovascular, including proximal vessel occlusion with or without bypass could not resolve this problem. Despite aggressive surgical treatment, the long-term outcome remains poor for most patients. ${ }^{26}$

Flow-diverting stents, available since 2007, seemed to be a therapeutic option. Data available in the literature on the use of flow-diverting stents, mostly case series, gave rise to optimism. In a series by Phillips et al, ${ }^{27} 32$ aneurysms of the posterior circulation were treated with flow-diverting stents. Mean aneurysm size was $9.7 \mathrm{~mm}$. Twenty aneurysms classified as fusiform, blister, sidewall, or dissecting were included. The authors reported a complete occlusion rate of $96 \%$ in a follow-up of $>12$ months. Fischer et $\mathrm{al}^{28}$ reported complete occlusion rates of $74 \%$ in combination with $4.54 \%$ morbidity and $2.27 \%$ mortality in a cohort of 88 patients (mean aneurysm size, $3.8 \mathrm{~mm} ; 22 \%$ posterior circulation). They included 63 (62\%) saccular aneurysms, 33 (33\%) fusiform aneurysms, and 5 (5\%) dissections. Finally, McAuliffe et 

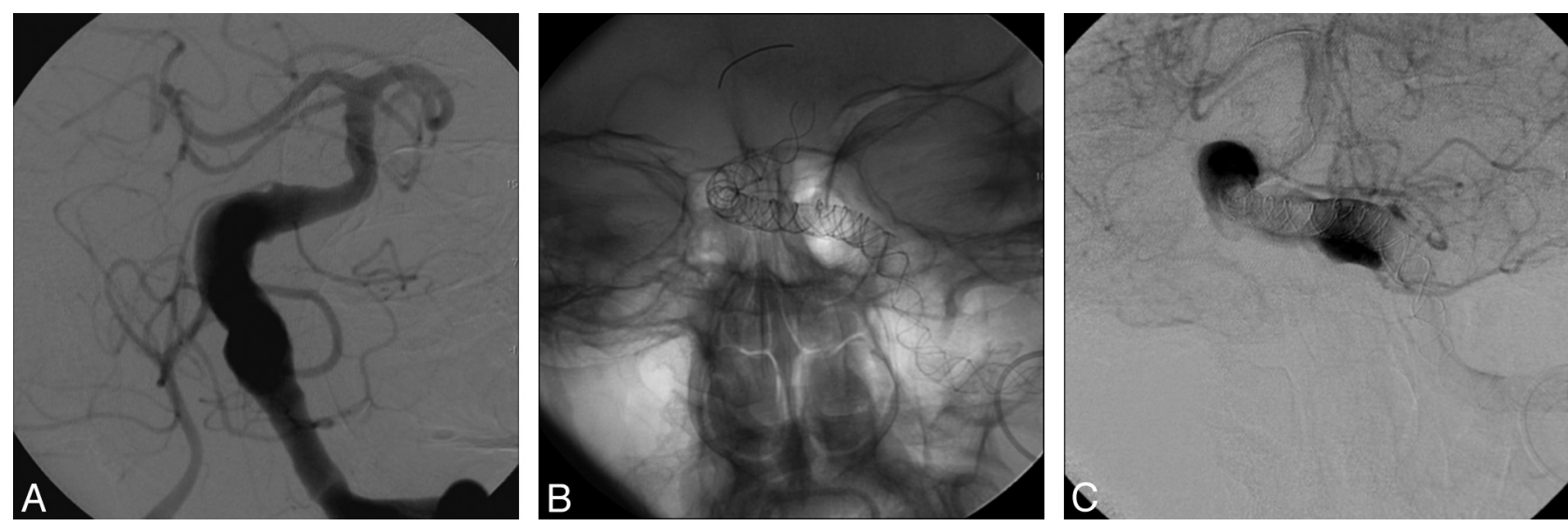

FIG 1. A, Patient 4, primary intervention. Anteroposterior view of a vertebral artery angiogram shows an FVBGA involving the distal V4 segment of the left vertebral artery. $B$, Patient 4, primary intervention. Anteroposterior view of a vertebral artery angiogram demonstrates the final stent position. C, Patient 4, primary intervention. Anteroposterior view of a vertebral artery angiogram shows patency of the stents with adjacent contrast agent pooling, indicating hemostasis inside the aneurysm.
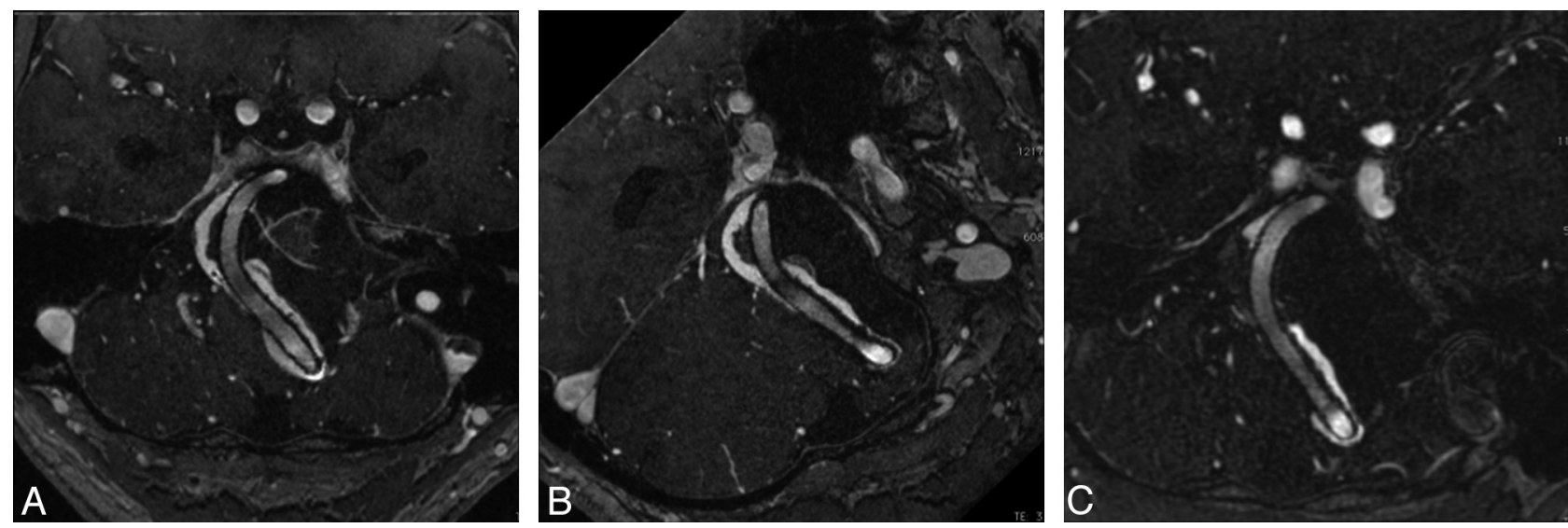

FIG 2. A, Patient $4, M R$ imaging during follow-up. Transverse contrast-enhanced MR angiography on day 3 after intervention shows patency of the stents with adjacent thrombus formation inside the aneurysm. B, Patient 4, MR imaging during follow-up. Transverse contrast-enhanced MR angiography on day 8 after the intervention shows patency of the stents with progressive-yet-incomplete thrombus formation inside the aneurysm. C, Patient 4, MR imaging during follow-up. Transverse contrast-enhanced MR angiography on day 39 after the intervention shows patency of the stents with progressive yet incomplete thrombus formation inside the aneurysm.

$\mathrm{al}^{29}$ reported 54 cases (19\% posterior circulation; mean aneurysm size, $13.1 \mathrm{~mm}$ ) with a complete occlusion rate of $85.7 \%$ in a 6 -month follow-up in combination with $0 \%$ morbidity and $0 \%$ mortality.

However, the problem with all these publications is that a statistically relevant extrapolation of data on the anatomic subtype of FVBGA is not feasible. Of the total of 32 aneurysms in the posterior circulation in the article by Phillips et al, ${ }^{27}$ only 8 were located in the basilar trunk. No detailed information on aneurysm morphology or giant subtype was provided. Fischer et $\mathrm{al}^{28}$ did not specifically address this aneurysm subtype. Furthermore, only $50 \%$ of their baseline collective had a 10-month follow-up. In the collective of McAuliffe et al, ${ }^{29}$ no differentiated information on performance of flow diverters in FVBGAs was provided and the total follow-up of all cases was not longer than 6 months. To sum up, despite positive results on the use of flow-diverting stents in other aneurysm types and/or anatomic locations, little has been reported on the complication rate of flow-diverting stents in the FVBGA subtype.

Siddiqui et $\mathrm{al}^{30}$ reported specifically on flow diversion in the treatment of large or giant fusiform vertebrobasilar aneurysms. The authors presented their initial results with this therapy approach, including significant morbidity and mortality encountered. Of the 7 patients treated with flow-diversion devices, 4 died. The authors "have opted to cease treating most large aneurysms of the entire basilar artery with flow-diversion techniques" until they "can gain further understanding of the hemodynamic effects on brain stem perforators." 30

Meckel et $\mathrm{al}^{31}$ also reported on 10 patients treated with flowdiverting stents in complex aneurysms at the vertebrobasilar junction. Six patients had a large or giant aneurysm of the fusiform subtype. Four of these 6 patients died during follow-up, and 1 of the remaining 2 patients was "lost to further follow-up after 6 months."

The preinterventional clinical course of our patients-some under observation for up to 4 years-continuously deteriorated and finally resulted in an interdisciplinary, patient-specific decision in favor of an experimental endovascular therapeutic approach. All patients were exposed to a high load of psychological strain and endured their chronically deteriorating disease with a poor history. Even if we cannot quantify this factor by means of a 
scored survey, it is not negligible because it represents a human factor in the decision-making process.

Primary procedural success was remarkably good, and the procedural complication rate was very low. As shown in Table 1, no technical problems occurred during deployment of the stents. Stent implantation and periprocedural management were performed according to all principles of good clinical practice and in line with the recommendations of the manufacturer. As indicated in Fig $1 A-C$, flow diversion with deceleration of blood flow in the aneurysm outside the implanted devices was demonstrable in all cases (Fig $1 A-C$ ). In addition, no clinical complications were observed within the first 24 hours after the initial intervention (Table 1).

However, the clinical course in the further follow-up was extremely poor. In 2 cases, stent occlusion occurred on days 9 and 32 (patients 3 and 4, respectively), leading to an immediately lifethreatening thrombotic occlusion of the basilar artery. Despite immediate medical and endovascular interventions, both patients had persistent grave neurologic deficits. Patient 3 was "locked-in" after this incident and died on day 15 after the primary intervention.

As shown in Fig $2 A-C$, thrombotic occlusion of the primary aneurysm was progressive but incomplete in 5 of 6 cases (Table 5 and Fig $2 A-C$ ). After a mean follow-up of 13 months, 4 of 6 patients had died. With an mRS score of 5 in the last follow-up, the remaining 2 patients also showed an extremely poor outcome compared with their preinterventional mRS values of 1 and 3 , respectively (patients 4 and 5, Table 6).

Although we cannot prove this statement, the clinical course in all cases was presumably worse than the known evidence-based data would suggest for the spontaneous natural history of the disease. Two patients died because of progressive mass effect of their FVBGAs in long-term follow-up. Steroidal treatment and other antiedema therapy always should be considered, of course, but in our cases, unfortunately, they were unable to stop continuous aneurysm growth and aggravating brain stem compression. Treatment with anticoagulants may seem to be justified in light of the high risk of ischemic stroke. However, the increased risk of intracranial hemorrhage might cause complications as well. Hence, no definite statement on medical treatment can be given. $^{32}$

An important limitation of our data needs to be discussed: The monocentric approach with 6 patients does not allow statistically valuable conclusions. However, because there are only a few publications on the use of flow-diverting stents in fusiform vertebrobasilar aneurysms in the literature, we consider our findings to be an important message to the neurointerventional community.

\section{CONCLUSIONS}

Endovascular treatment of FVBGAs with flow-diverting devices is feasible from a technical point of view and did not cause any immediate periprocedural complications. However, changes in hemodynamics with secondary thrombosis are not predictable. The patency of brain stem perforators intended to have continuing ability to draw blood through the flow-diversion devices cannot be guaranteed. Evidence on the natural history of this aneurysm subtype is poor; this knowledge hinders treatment decisions.
Despite all limitations, we believe that out treatment effort worsened rather than positively affected the individual prognosis of our patients. In accordance with other authors, we currently do not intend to treat fusiform vertebrobasilar giant aneurysms with flow-diverting devices until we have gained further understanding of the pathophysiology, natural history, and hemodynamic effects of flow-diversion devices on FVBGAs. We strongly encourage the publication of the experiences of other centers of this challenging and yet not appropriately treatable aneurysm subtype.

Disclosures: Markus Holtmannspötter-UNRELATED: Consultancy: Covidien, MicroVention, Sequent Medical, Comments: proctor and consultant for Covidien/ev3 and Sequent Medical, consultant for MicroVention, Payment for Lectures (including service on Speakers Bureaus): Covidien, MicroVention, Sequent Medical, Travel/ Accommodations/Meeting Expenses Unrelated to Activities Listed: Codman, Stryker.

\section{REFERENCES}

1. Miller JD, Jawad K, Jennett B. Safety of carotid ligation and its role in the management of intracranial aneurysms. J Neurol Neurosurg Psychiatry 1977;40:64-72

2. Lawton MT, Spetzler RF. Surgical strategies for giant intracranial aneurysms. Neurosurg Clin N Am 1998;9:725-42

3. Sadik AR, Budzilovich GN, Shulman K. Giant aneurysm of middle cerebral artery: a case report. J Neurosurg 1965;22:177-81

4. McCormick WF, Acosta-Rua GJ. The size of intracranial saccular aneurysms: an autopsy study. J Neurosurg. 1970;33:422-27

5. Drake CG. Giant intracranial aneurysms: experience with surgical treatment in 174 patients. Clin Neurosurg 1979;26:12-95

6. Hosobuchi Y. Direct surgical treatment of giant intracranial aneurysms. J Neurosurg 1979;51:743-56

7. Locksley HB, Sahs AL, Sandler R. Report on the cooperative study of intracranial aneurysms and subarachnoid hemorrhage. 3. Subarachnoid hemorrhage unrelated to intracranial aneurysm and A-V malformation - a study of associated diseases and prognosis. J Neurosurg 1966;24:1034-56

8. Pia HW, Zierski J. Giant cerebral aneurysms. Neurosurg Rev 1982;5:117-48

9. Rinne J, Hernesniemi J, Niskanen M, et al. Analysis of 561 patients with 690 middle cerebral artery aneurysms: anatomic and clinical features as correlated to management outcome. Neurosurgery 1996;38:2-11

10. Drake CG, Peerless SJ. Giant fusiform intracranial aneurysms: review of 120 patients treated surgically from 1965 to 1992 . J Neurosurg 1997;87:141-62

11. German WJ, Black SP. Intra-aneurysmal hemodynamics-jet action. Circ Res 1955;3:463-68

12. Choi IS, David C. Giant intracranial aneurysms: development, clinical presentation and treatment. Eur J Radiol 2003;46:178-94

13. Flemming KD, Wiebers DO, Brown RD Jr, et al. Prospective risk of hemorrhage in patients with vertebrobasilar nonsaccular intracranial aneurysm. J Neurosurg 2004;101:82-87

14. Flemming KD, Wiebers DO, Brown RD Jr, et al. The natural history of radiographically defined vertebrobasilar nonsaccular intracranial aneurysms. Cerebrovasc Dis 2005;20:270-79

15. Gonzalez NR, Duckwiler G, Jahan R, et al. Challenges in the endovascular treatment of giant intracranial aneurysms. Neurosurgery 2006;62(6 suppl 3):1324-35

16. Fiorella D, Kelly ME, Albuquerque FC, et al. Curative reconstruction of a giant midbasilar trunk aneurysm with the Pipeline embolization device. Neurosurgery 2009;64:212-17

17. Fiorella D, Woo HH, Albuquerque FC, et al. Definitive reconstruction of circumferential, fusiform intracranial aneurysms with the Pipeline embolization device. Neurosurgery 2008;62:1115-20, discussion 1120-21 
18. Nelson PK, Lylyk P, Szikora I, et al. The Pipeline embolization device for the intracranial treatment of aneurysms trial. AJNR Am J Neuroradiol 2011;32:34-40

19. Rankin J. Cerebral vascular accidents in patients over the age of 60. II. Prognosis. Scott Med J 1957;2:200-15

20. Duncan PW, Jorgensen HS, Wade DT. Outcome measures in acute stroke trials: a systematic review and some recommendations to improve practice. Stroke 2000;31:1429-38

21. Wong GK, Lau JC, Poon WS. Flow diverting stents for cerebral aneurysm treatment: time to replace coiling? J Clin Neurosci 2011; 18:1143

22. Pumar JM, Blanco M, Vazquez F, et al. Preliminary experience with Leo self-expanding stent for the treatment of intracranial aneurysms. AJNR Am J Neuroradiol 2005;26:2573-77

23. Raphaeli G, Collignon L, De Witte O, et al. Endovascular treatment of posterior circulation fusiform aneurysms: single-center experience in 31 patients. Neurosurgery 2011;69:274-83

24. Echiverri HC, Rubino FA, Gupta SR, et al. Fusiform aneurysm of the vertebrobasilar arterial system. Stroke 1989;20:1741-47

25. Mizutani T, Miki Y, Kojima H, et al. Proposed classification of nonatherosclerotic cerebral fusiform and dissecting aneurysms. Neurosurgery 1999;45:253-59

26. Kalani MY, Zabramski JM, Nakaji P, et al. Bypass and flow reduction for complex basilar and vertebrobasilar junction aneurysms. $\mathrm{Neu}$ rosurgery 2013;72:763-76, discussion 775-76

27. Phillips TJ, Wenderoth JD, Phatouros CC, et al. Safety of the Pipeline embolization device in treatment of posterior circulation aneurysms. AJNR Am J Neuroradiol 2012;33:1225-31

28. Fischer S, Vajda Z, Aguilar PM, et al. Pipeline embolization device (PED) for neurovascular reconstruction: initial experience in the treatment of 101 intracranial aneurysms and dissections. Neuroradiology 2012;54:369-82

29. McAuliffe W, Wycoco V, Rice H, et al. Immediate and midterm results following treatment of unruptured intracranial aneurysms with the Pipeline embolization device. AJNR Am J Neuroradiol 2012;33:164-70

30. Siddiqui AH, Abla AA, Kan P, et al. Panacea or problem: flow diverters in the treatment of symptomatic large or giant fusiform vertebrobasilar aneurysms. J Neurosurg 2012;116:1258-66

31. Meckel S, McAuliffe W, Fiorella D, et al. Endovascular treatment of complex aneurysms at the vertebrobasilar junction with flow-diverting stents: initial experience. Neurosurgery 2013;73: 386-94

32. Wolters FJ, Rinkel GJ, Vergouwen MD. Clinical course and treatment of vertebrobasilar dolichoectasia: a systematic review of the literature. Neurol Res 2013;35:131-37 